\title{
Seismic fragility analysis for tall pier bridges with rocking foundations
}

\author{
Xu Chen ${ }^{1,2,3^{*}}$ and Jianzhong $\mathrm{Li}^{4}$
}

\author{
* Correspondence: xuchen_shu@ \\ 163.com \\ ${ }^{1}$ Shanghai Key Laboratory of \\ Mechanics in Energy Engineering, \\ Shanghai, China \\ ${ }^{2}$ Shanghai Institute of Applied \\ Mathematics and Mechanics, \\ Shanghai, China \\ Full list of author information is \\ available at the end of the article
}

\begin{abstract}
Costal bridge systems usually contain tall piers with heights over $40 \mathrm{~m}$, due to the engineering site exposed to deep water circumstances. Note that the conventional seismic isolation devices (e.g., isolation bearings) are not that effective for tall piers, since their dynamic performance is significantly affected by the distributed mass and vibration modes of columns; therefore, base isolation design philosophy could be a promising alternative for mitigating seismic demands of this type of bridges. This paper mainly investigates the efficiency of rocking foundations in improving seismic performance of tall pier bridges, with the results presented in the format of fragility curves. Finite element model of the prototype tall pier bridge is developed, and the responses subjected to near-fault motions are obtained using nonlinear time history analysis. Probability seismic demand models and fragility curves are then developed accordingly, based on which the performance of tall pier bridges are assessed. The results show that employment of rocking foundations could significantly reduce the demands of tall piers and the probability of being damaged. Before the initiation of uplifting at pier base, the behavior of rocking piers resembles that of conventional ones with integrated foundation. While rocking initiates under strong excitations, the demands of rocking piers reduce drastically compared with integrated ones and tend to be similar under different motions, which benefits the post-earthquake performance assessment of these bridges.
\end{abstract}

Keywords: Tall pier bridges, Near-fault motions, Rocking foundations, Fragility analysis, Seismic performance

\section{Introduction}

Numerous coastal highway bridges have been constructed in recent decades, among which tall piers could be widely observed since the engineering sites are usually exposed to deep water circumstances (Liu et al. 2007; Deng et al. 2017). Current investigations showed that the seismic performance of tall piers is significantly affected by the distributed masses and vibration modes of columns, which differed from conventional short-to-medium piers Chen et al. (2016, 2018b, (2019; Chen and Guan (2020), 2018a, 2018b) pointed out that due to the higher-order modes, the seismic shear force and bending moment demands of tall piers could several times greater than those computed with capacity-protect method employed in current codes. Therefore, how to improve the seismic performance of tall piers deserve careful investigations.

(c) The Author(s). 2021 Open Access This article is licensed under a Creative Commons Attribution 4.0 International License, which permits use, sharing, adaptation, distribution and reproduction in any medium or format, as long as you give appropriate credit to the original author(s) and the source, provide a link to the Creative Commons licence, and indicate if changes were made. The images or other third party material in this article are included in the article's Creative Commons licence, unless indicated otherwise in a credit line to the material. If material is not included in the article's Creative Commons licence and your intended use is not permitted by statutory regulation or exceeds the permitted use, you will need to obtain permission directly from the copyright holder. To view a copy of this licence, visit http://creativecommons.org/licenses/by/4.0/. 
For conventional bridges with short-to-medium piers, one of the most commonly employed seismic isolation design strategy is to implement isolation bearings between girders and piers (Jangid 2007; Chen et al. 2009; Kelly and Konstantinidis 2011), including lead rubber bearings (LRB), friction pendulum bearings (FPB), and high-damping rubber bearings (HDRB). These bearings protect the piers through mitigating the lateral inertial force transmitted from the superstructures, as well as increasing the structural damping vibration periods (Yamamoto et al. 2012). However, these devices were demonstrated not be that efficient for tall piers, since the inertial force of columns could not be reduced (Chen and Li 2020a).

Alternatively, implementing base isolation for tall pier bridges might be a promising approach improving their seismic performance. From previous numerical (Xie et al. 2019) and experimental (Solberg et al. 2009) investigations, rocking foundation was shown as an effective design strategy mitigating the contribution of columns, which, however, were mainly focused on short-to-medium piers. While rocking foundation has been applied on existing tall pier bridges (e.g., Rio Vista Bridge (Yashinsky and Karshenas 2003), North Approach Viaduct of the Lions Gate Bridge (Dowdell and Hamersley 2000)), analytical analysis on these rocking tall piers is still limited.

Current study concentrates on the seismic performance tall piers employing rocking foundations, with the results presented in the format of fragility curves. Finite element models of the prototype tall pier bridge, as well as that using rocking foundations, are developed, and the seismic responses subjected to near-fault ground motions are obtained using nonlinear time history analysis (NTHA). Probability seismic demand models (PSDMs) and fragility curves are then developed accordingly, based on which the performance of tall pier bridges are assessed.

\section{Bridge prototype and numerical model}

\subsection{Bridge prototype}

A typical tall pier bridge might occur in coastal bridge systems is employed for study, as shown in Fig. 1. This prototype consists of $4 \times 30 \mathrm{~m}$ continuous pre-cast $\mathrm{T}$-shaped girders, with width and heights of $12 \mathrm{~m}$ and $2 \mathrm{~m}$, respectively. Totally $10 \mathrm{GJZ} 300 \times 300 \times 61$ rectangular rubber bearings are implemented at the top of each pier. The piers are composed of variable hollow sections with dimensions changing from $2.1 \mathrm{~m} \times 5.0 \mathrm{~m}$ (pier top) to 3.5 $\mathrm{m} \times 5.0 \mathrm{~m}$ (pier base), and the wall thickness is $0.6 \mathrm{~m}$ along the height (shown in Fig. 1).

To improve the system stability, an expanded pier base is design for rocking pier as shown in Fig. 2. The dimensions of pier base are $6.0 \mathrm{~m}$ and $7.0 \mathrm{~m}$ in longitudinal and transverse directions, respectively, while the height is $1.0 \mathrm{~m}$. The pier column is expected to rotate around the two corners (i.e., point $\mathrm{O}$ and $\mathrm{O}$ ' in Fig. 2) when subjected to strong earthquakes. Note that before initiation of uplifting at pier base, the rocking pier with expanded base would remain contact with pile cap, and thus perform identical to its monolithic counterparts.

\subsection{Numerical model}

Due to the regular mass and stiffness distribution of the prototype bridge, one column (shadowed in Fig. 1) is extracted for analysis in this study, which is simplified and represented as a cantilever beam to focus on the seismic behavior of pier columns. The corresponding numerical model is developed using OpenSees platform as shown in 


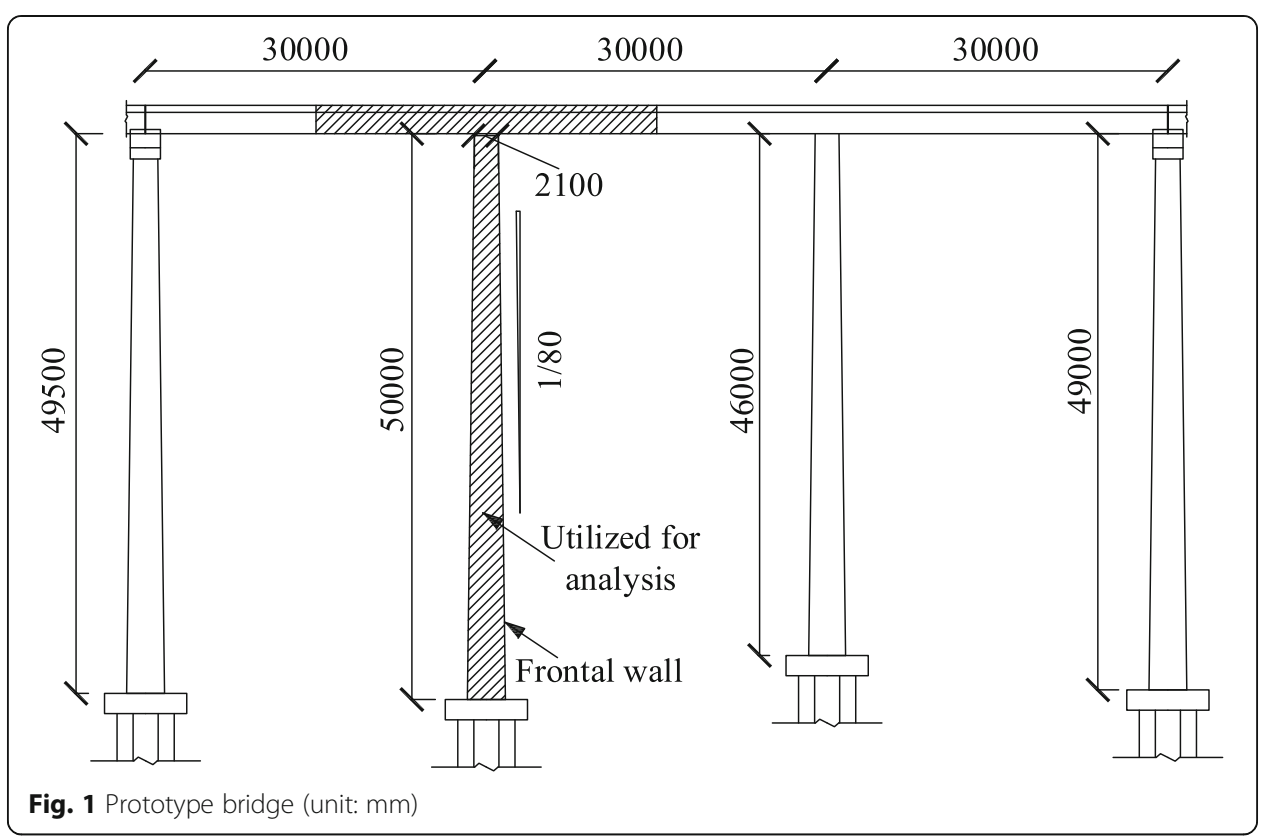

Fig. 3 (a). The distributed masses of column are simulated at nodes of pier element $(m)$, while the tributary mass of adjacent half spans are designated at the pier top $\left(\mathrm{M}_{1}\right)$. Due to the large pier height, the P- $\Delta$ effect is incorporated during simulation, while the soil-structure-interaction (SSI) effect is neglected since the flexibility of tall pier bridges is generally dominated by the pier column.

To consider the nonlinear property, the bilinear material as shown in Fig. 3 (b) is employed to simulate the rubber bearings. The post-yielding stiffness $k_{2}$ and yield strength $f_{\text {by }}$ could be computed through (Wang, et al. 2019):

$$
\begin{aligned}
& k_{2}=G_{b} A_{b} / t_{r} \\
& f_{b y}=k_{1} / \delta_{b y}
\end{aligned}
$$

where $G_{b}, A_{b}$ and $t_{r}$ denote the shear modulus, area and total thickness of rubber layers; initial stiffness $k_{1}=10 \cdot k_{2}$; yield displacement $\delta_{b y}=0.075 \cdot t_{r}$.

While modelling the reinforced concrete pier columns, force-based nonlinear fiber elements are adopted, accounting for the potential nonlinear behavior when subjected to

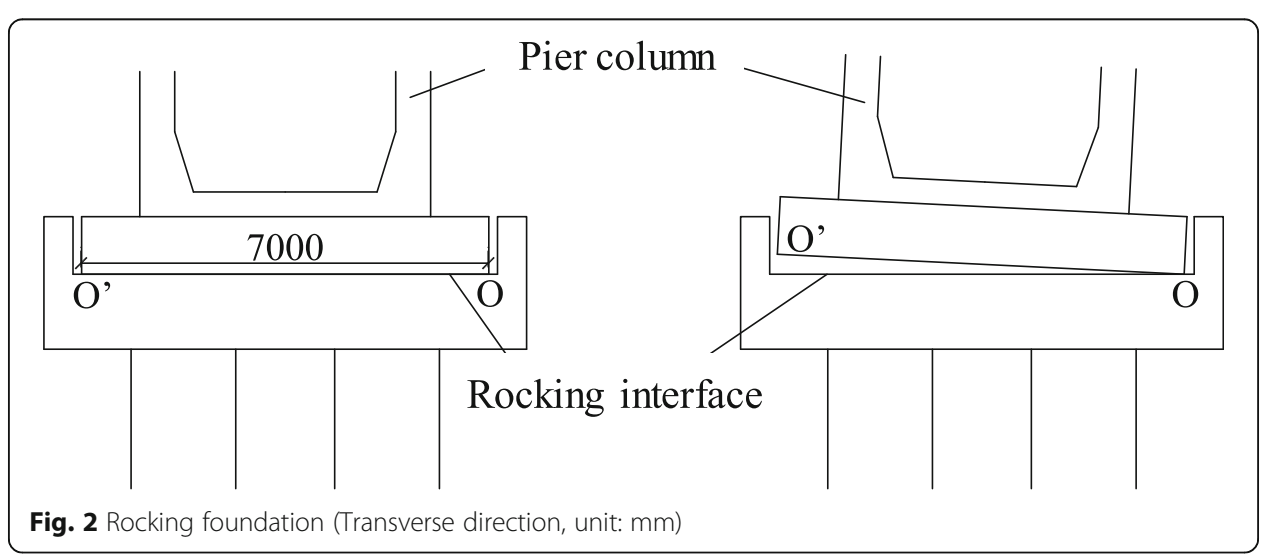




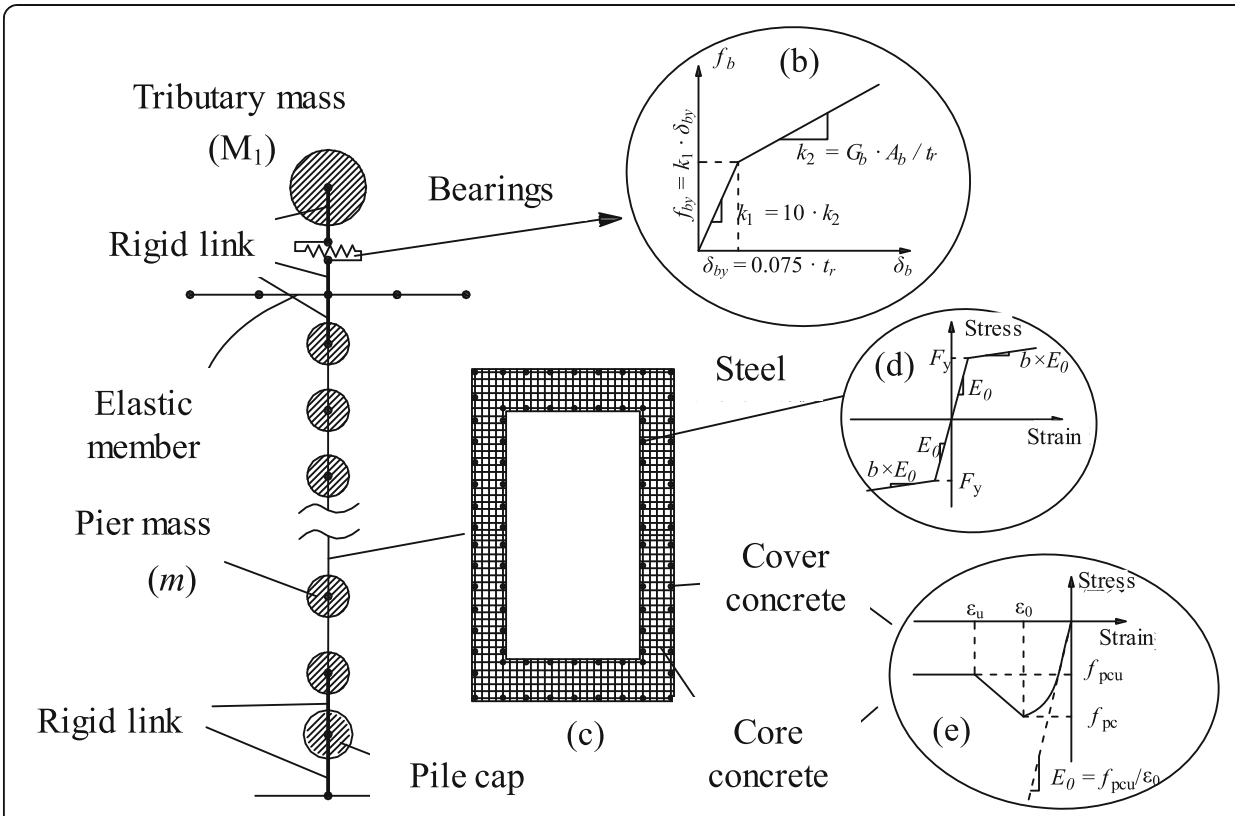

(a)

Fig. 3 Finite element model: (a) cantilever model; (b) force-deformation relationship of bearings; (c) fiber element section; constitutive relationship of (d) steel and (e) concrete

strong earthquakes. As shown in Fig. 3 (c), the cross sections are subdivided into steel and concrete fibers (confined and unconfined), the constitutive relations of which are simulated with Giuffre-Menegotto-Pinto (Guirguis and Mehanny 2012) and Kent-Scott-Park (Scott et al. 1982) model, respectively (shown in Fig. 3 (d) and (e)).

For simulation of the rocking interface, sufficient friction is assumed to avoid sliding between pier base and pile cap. 81 elastic-no-tension (ENT) spring elements are employed to present the rocking behavior, as plotted in Fig. 4. According to the articles in FEMA 356, these ENT springs are classified into 3 categories, and named as 'end zone' (Zone 1 and 2) and 'middle zone' (Zone 3) as shown in Fig. 4 (b) (Chen and Li $2020 \mathrm{~b})$. The end zones are defined as regions at each side of foundations from the margin to $1 / 6$ of the width in the perpendicular direction; and other parts are the middle zones. This classification is originally proposed for shallow bearing foundations; while in this paper, the pier base and pile cap could be regarded as shallow foundation and supporting soil, respectively, and the pier base is not rigid with respect to the pile cap. The stiffness of per unit area for each spring could be estimated using Eqs. (3) and (4). More details could be found in FEMA 356.

$$
\begin{aligned}
& k_{\text {Zoneland2 }}=6.83 \mathrm{G} /(1-\nu) \\
& k_{\text {Zone3 }}=0.73 \mathrm{G} /(1-\nu)
\end{aligned}
$$

in which $\mathrm{G}$ and $\nu$ are the shear modulus and Poisson ratio of material at rocking interface, respectively. 


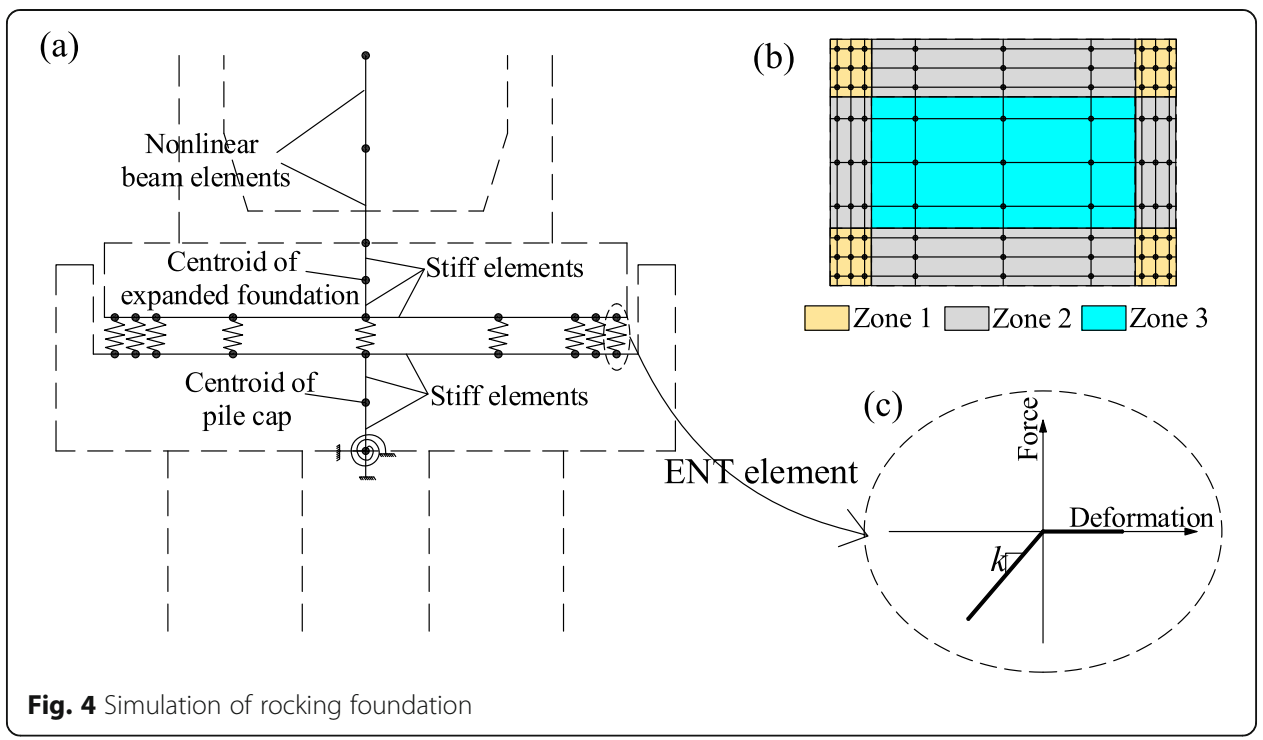

\section{Seismic fragility analysis methodology}

Seismic fragility analysis has been recognized as an effective approach to investigate the vulnerability of structures under earthquakes, which provides a means to connect the probability of being damaged over a range of potential ground motion intensities (Padgett and DesRoches 2008). The fragility function actually shows the conditional probability of structural demands exceeding pre-specified damage level for a given earthquake intensity (Tekie and Ellingwood 2003, Chen 2020), and could be expressed as:

$$
\text { Fragility }=\mathrm{P}[\mathrm{D} \geq \mathrm{C} \mid \mathrm{IM}=\mathrm{y}]
$$

in which $D$ and $C$ denote the structural demand and the capacity of damage limit states, respectively; $I M$ is the intensity measure of input ground motions, e.g., peak ground acceleration (PGA), peak ground velocity (PGV), and spectral acceleration at certain period $\left(\mathrm{S}_{\mathrm{a}}(\mathrm{T})\right) ; y$ is the given value of $I M$.

To develop the fragility function shown in Eq. (5), the relation between engineering demand parameter (EDP) of structures and $I M$ is required, and named as probabilistic seismic demand models (PSDMs) (Nielson and DesRoches 2007). According to previous investigations (Cornell et al. 2002), these two parameters generally follow the power-law function:

$$
E D P=a \mathrm{IM}^{b} \text { orln }(\mathrm{EDP})=\ln (\mathrm{a})+\mathrm{bln}(\mathrm{IM})
$$

where $a$ and $b$ are unknown regression coefficients, which could be obtained from regression analysis. When further assuming that the structural demand and capacity follow lognormal distribution (Gardoni et al. 2003), the seismic fragility, i.e., the failure probability of a damage states conditioned on a given $I M$, could be computed by: 


$$
P_{\mathrm{f}}=P[E D P \geq L S \mid \mathrm{IM}]=\Phi\left(\frac{\ln \left(\mathrm{S}_{\mathrm{d}}\right)-\ln \left(\mathrm{S}_{\mathrm{C}}\right)}{\sqrt{\beta_{\mathrm{EDP} \mid \mathrm{IM}}^{2}+\beta_{\mathrm{C}}^{2}}}\right)
$$

in which $\Phi(\cdot)$ is the standard normal cumulative distribution function; $S_{d}$ and $S_{c}$ are the median values of EDP and structural capacity, respectively; $\beta_{C}$ means the dispersion of damage state capacity, while $\beta_{D \mid I M}$ denotes the dispersion of demand conditioned on IM and can be expressed as (Alam et al. 2012):

$$
\beta_{D \mid \mathrm{IM}}=\sqrt{\frac{\sum_{i}^{N}\left(\ln \left(\mathrm{EDP}_{\mathrm{i}}\right)-\left(\ln (\mathrm{a})+\mathrm{bln}\left(\mathrm{IM}_{\mathrm{i}}\right)\right)\right)^{2}}{N-2}}
$$

where $N$ is the number of total simulation cases, and $i$ is the $i$ th realization.

\section{Seismic assessment of rocking foundation}

\subsection{Selection of input motions}

Although current seismic design specifications generally consider the far-field motions as inputs, provided studies have shown that near-fault excitations might lead to more devastating damage to structures, especially the flexible ones as tall pier bridges (Phan et al. 2007). Consequently, this paper employs 40 near-fault motions selected from PEER database as input motions. Details of these motions are listed in Table 1, in which all the parameters are obtained using the algorithm proposed by Zhao, et al. (Zhao et al. 2016).

Furthermore, to generate sufficient data for the development of PSDM, each motion listed in Table 1 is scaled with 4 factors, namely 0.5, 1.0, 1.5 and 2.0. Note that the scaling factors are limited less than 2.0 to avoid overly-scaling-induced structural response biases (Sica et al. 2013). Finally, $4 \times 40=160$ motions in total are generated and used as inputs for nonlinear time history analysis, obtaining the seismic responses and constructing PSDMs.

Note that the prototype tall piers are simplified and represented by single column cantilever models as shown in Fig. 3. Thus, the pier model is expected to perform with similar tendency in longitudinal and transverse directions, while the detailed demand values could be different due to the rectangular configuration of pier sections. Consequently, these input motions are only considered in longitudinal direction in the following analysis, to avoid data redundancy.

\subsection{Limit states and proper intensity measure (IM)}

Definition of various damage states and the corresponding quantitative measures is pre-requisite for assessing seismic fragility of structures. Here in this paper, four damage states (i.e., slight, moderate, extensive and complete) used in previous literatures are employed (Chen and Li 2020a). As demonstrated in previous experimental and numerical studies (Chen et al. 2018a, b), the displacement at the top of tall piers was not highly correlated to the section curvature at pier base, due to the distributed masses and higher-order modes of columns. This conclusion denotes that displacement cannot be employed as damage index as in the case of conventional short-to-medium piers. 
Table 1 Near-fault motions

\begin{tabular}{|c|c|c|c|c|c|c|c|}
\hline No. & Events & Year & Magnitude & Station & PGA(g) & $\mathrm{PGV}(\mathrm{cm} / \mathrm{s})$ & $\mathrm{T}_{\mathrm{v}}(\mathrm{s})$ \\
\hline E1 & Parkfield & 1966 & 6.1 & Temblor & 1.34 & 62.21 & 0.67 \\
\hline E2 & San Fernando & 1971 & 6.6 & Pacoima dam & 0.16 & 40.17 & 4.71 \\
\hline E3 & Imperial valley-06 & 1979 & 6.5 & Brawley airport & 0.22 & 72.98 & 3.72 \\
\hline E4 & & & & EC County center FF & 0.20 & 53.17 & 3.93 \\
\hline E5 & & & & EC Meloland overpass FF & 0.27 & 58.42 & 2.92 \\
\hline E6 & & & & El Centro array \#3 & 0.38 & 97.94 & 3.52 \\
\hline E7 & & & & El Centro array \#4 & 0.44 & 123.96 & 3.26 \\
\hline E8 & & & & El Centro array \#5 & 0.46 & 112.07 & 3.17 \\
\hline E9 & & & & El Centro array \#6 & 0.57 & 72.18 & 5.17 \\
\hline E10 & & & & El Centro array \#7 & 0.35 & 76.46 & 2.72 \\
\hline E11 & & & & El Centro array \#8 & 0.23 & 75.08 & 3.85 \\
\hline E12 & & & & Holtville post office & 1.30 & 79.96 & 0.80 \\
\hline E13 & & & & Westmorland fire sta & 0.26 & 37.97 & 1.14 \\
\hline E14 & Morgan hill & 1984 & 6.2 & Gilroy array \#6 & 0.45 & 144.54 & 2.32 \\
\hline E15 & Supersition hill & 1987 & 6.6 & El Centro Imp. Co. Cent & 0.33 & 32.85 & 0.41 \\
\hline E16 & & & & Parachute Test Site & 0.27 & 44.58 & 1.32 \\
\hline E17 & Loma Prieta & 1989 & 7.0 & Gilroy - Gavilan Coll. & 0.46 & 37.97 & 0.41 \\
\hline E18 & & & & Gilroy Array \#1 & 0.37 & 46.37 & 2.16 \\
\hline E19 & & & & Gilroy Array \#2 & 0.61 & 103.80 & 0.74 \\
\hline E20 & & & & Gilroy Array \#3 & 0.32 & 58.33 & 1.67 \\
\hline E21 & & & & LGPC & 0.37 & 73.03 & 1.19 \\
\hline E22 & & & & Saratoga - Aloha Ave & 0.43 & 119.75 & 2.10 \\
\hline E23 & & & & Saratoga - W Valley Coll. & 0.72 & 135.25 & 4.66 \\
\hline E24 & Erzincan, Turkey & 1992 & 6.7 & Erzincan & 0.45 & 100.68 & 2.54 \\
\hline E25 & Landers & 1992 & 7.3 & Lucerne & 0.43 & 76.29 & 1.28 \\
\hline E26 & Northridge & 1994 & 6.7 & Jensen Filter Plant & 0.71 & 119.91 & 1.26 \\
\hline E27 & & & & LA Dam & 0.42 & 120.79 & 2.09 \\
\hline E28 & & & & Pacoima Dam (downstr) & 0.85 & 146.33 & 1.06 \\
\hline E29 & & & & Sylmar - Converter Sta & 0.75 & 127.84 & 2.59 \\
\hline E30 & & & & Sylmar - Olive View Med FF & 0.30 & 56.61 & 1.31 \\
\hline E31 & Kobe & 1995 & 6.9 & Kobe University & 0.43 & 104.70 & 1.35 \\
\hline E32 & & & & OSAJ & 0.13 & 41.14 & 5.75 \\
\hline E33 & & & & Port Island (0 m) & 0.32 & 60.86 & 3.91 \\
\hline E34 & Kocaeli & 1999 & 7.4 & Arcelik & 0.19 & 53.73 & 4.54 \\
\hline E35 & & & & Duzce & 0.51 & 213.31 & 12.8 \\
\hline E36 & & & & Gebze & 0.47 & 348.82 & 10.2 \\
\hline E37 & Chi-Chi & 1999 & 7.6 & TCU052 & 0.32 & 109.24 & 4.44 \\
\hline E38 & & & & TCU068 & 0.20 & 73.51 & 8.39 \\
\hline E39 & & & & TCU075 & 0.27 & 114.84 & 2.55 \\
\hline E40 & & & & TCU101 & 0.13 & 68.60 & 7.81 \\
\hline
\end{tabular}


Therefore, the section curvature ductility $\left(\mu_{\phi}\right)$ is utilized herein as suggested by shake table tests (Chen et al. 2018a). The thresholds for each damage state recommended by Neilson and DesRoches (2007) are employed and presented in Table 2.

Selection of proper intensity measure $(I M)$ is another significant aspect for seismic fragility analysis. Generally, various parameters could be candidates, among which PGA, PGV and PGD are commonly employed ones. Previous investigations show that the performance of $I M$ s could be evaluated through efficiency, practicality and proficiency (Luco and Cornell 2007; Padgett et al. 2008). A more efficient $I M$ leads to less dispersion and could be represented by a lower value of $\beta_{D \mid I M}$; while a more practical IM is usually measured by a higher value of regression parameter $b$. The proficiency is evaluated through a combined measure ( $\xi$ ) denoting the ratio between $\beta_{D \mid I M}$ and $b$, and a lower generally indicates a better $I M$.

To find out a proper $I M$, current study computes and compares the performance of PGA, PGV and PGD in terms of efficiency, practicality and proficiency. The results are listed in Table 3, which shows that the PGV possesses greatest $b$ value, as well as lowest $\beta_{D \mid I M}$ and $\xi$ for all scenarios considered, indicating PGV a better IM compared with PGA and PGD. Consequently, PGV will be employed as $I M$ in the following analysis, to develop more reliable PSDMs and fragility curves

Note that the response mechanism of rocking piers depends on whether uplifting initiates during earthquakes, which is related to the input intensity of input motions. Therefore, the parameters $\left(b, \beta_{D \mid I M}\right.$ and $\left.\xi\right)$ for rocking piers are presented for moderate and strong excitations, which corresponds to contact and rotating of rocking interface, respectively. More details about this issue will be presented and discussed in the following section

\subsection{Probability seismic demand models (PSDMs)}

Figure 5 shows the PSDMs for the prototype and rocking pier bridges, as well as the linear regression results for each case; while the corresponding parameters are listed in Table 4. From Fig. 5, the performance of rocking pier is observed resembling that of prototype (integrated) pier when motions with low intensity are considered. However, with the increase of PGV, rocking foundations could significantly mitigate the seismic demands of $\mu_{\phi}$. While the PSDM of prototype could be presented linearly as shown in Fig. 5, that of rocking pier should be simulated in a bi-linear manner (black line in Fig. 5). From this figure, the inflection point of the polyline approximately occurs with $\ln (\mathrm{PGV})=4.5$, i.e., $\mathrm{PGV} \approx 90 \mathrm{~cm} / \mathrm{s}$, which is used to classify the moderate and strong excitation in Table 3.

This phenomenon is due to the change of dominant dynamic mechanism of rocking piers during earthquake events. Under moderate earthquake excitations, uplifting does not initiate at the rocking interface, and the performance of rocking piers is dominated by the flexural deformation of columns, which is similar to its integrate counterpart

Table 2 Damage states of pier column

\begin{tabular}{lcccc}
\hline Damage states & Slight & Moderate & Extensive & Complete \\
\hline$S_{c}$ & 1.29 & 2.10 & 3.52 & 5.24 \\
$\beta_{c}$ & 0.59 & 0.51 & 0.64 & 0.65 \\
\hline
\end{tabular}


Table 3 Comparisons of various IM in terms of efficiency, practicality and proficiency

\begin{tabular}{|c|c|c|c|c|c|c|c|c|c|}
\hline \multirow{3}{*}{$\begin{array}{l}\text { Scenarios } \\
\mathrm{IMs}\end{array}$} & \multirow{2}{*}{\multicolumn{3}{|c|}{ Prototype }} & \multicolumn{6}{|c|}{ Rocking piers } \\
\hline & & & & \multicolumn{3}{|c|}{ Moderate excitation } & \multicolumn{3}{|c|}{ Strong excitation } \\
\hline & $b$ & $\beta_{D|| M}$ & $\xi$ & $b$ & $\beta_{\mathrm{D} \mid \mathrm{M}}$ & $\xi$ & $b$ & $\beta_{D|| M}$ & $\xi$ \\
\hline PGA & 0.752 & 0.630 & 0.838 & 0.289 & 0.786 & 2.717 & 0.141 & 0.340 & 2.417 \\
\hline PGV & 1.095 & 0.302 & 0.276 & 0.877 & 0.310 & 0.353 & 0.164 & 0.070 & 0.424 \\
\hline PGD & 0.538 & 0.607 & 1.128 & 0.220 & 0.866 & 3.944 & 0.030 & 0.106 & 3.590 \\
\hline
\end{tabular}

(denoted in Fig. 5 by black circle). While strong earthquakes are considered, the rigid body rotation becomes the dominant for rocking pier, which functions as base isolation and reduce the demands of columns (denoted in Fig. 5 by red circle).

To better illustrate this change of response mechanism, analytical explanation is briefly provided here. For the rocking pier designed in current study (shown in Fig. 2), the maximum bending moment at pier base before uplifting equals the resistance $\left(M_{r}\right)$ provided by the self-weight of pier column and superstructure, which could be estimated as:

$$
\mathrm{M}_{r}=\left(\sum m_{i}+\mathrm{M}_{1}\right) g \times b / 2
$$

in which $\mathrm{M}_{1}$ and $m_{i}$ are the mass of the superstructure and the $i$ th column node, respectively.

When rocking initiates, the bending moment at pier base will roughly remain constant of $\mathrm{M}_{\mathrm{r}}$. Thus, the maximum curvature ductility $\left(\phi_{r}\right)$ can be computed by Eq. (10), where $\mathrm{M}_{y}$ and $\phi_{y}$ are the yielding moment and yielding curvature of pier base section.

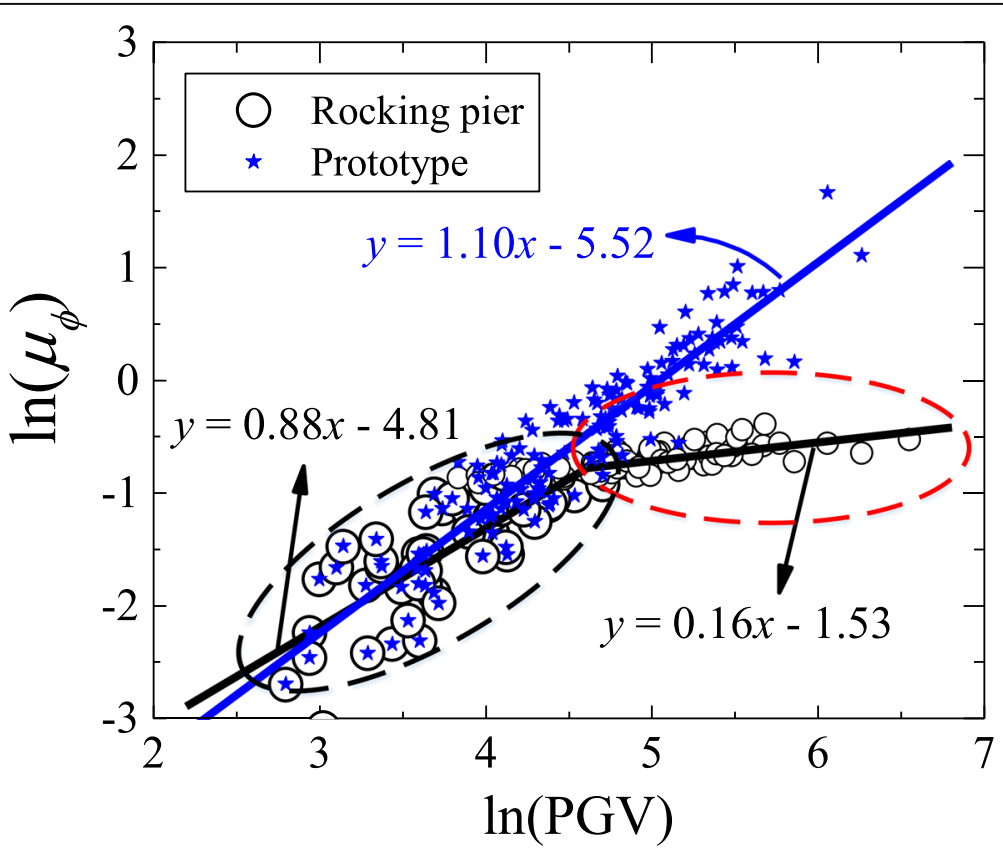

Fig. 5 PSDM for prototype and rocking foundation bridges 
Table 4 Parameters of PSDMs

\begin{tabular}{lllll}
\hline Scenarios & & $\ln (\boldsymbol{a})$ & $\boldsymbol{b}$ & $\beta_{\mathrm{D} \mid \mathrm{M}}$ \\
\hline Prototype & & -5.522 & 1.095 & 0.638 \\
Rocking pier & $\mathrm{PGV}<90 \mathrm{~cm} / \mathrm{s}$ & -4.814 & 0.877 & 0.310 \\
& $\mathrm{PGV}>90 \mathrm{~cm} / \mathrm{s}$ & -1.531 & 0.164 & 0.070 \\
\hline
\end{tabular}

$$
\phi_{\mathrm{r}}=\left(\mathrm{M}_{\mathrm{r}} / \mathrm{M}_{\mathrm{y}}\right) \phi_{\mathrm{y}}
$$

By using results of moment-curvature (M- $\phi)$ analysis for the pier base section and Eq. (10), the $\phi_{\mathrm{r}}$ value of current rocking pier is estimated around $0.407 \times 10^{-3} \mathrm{rad} / \mathrm{m}$. All the responses in red circle of Fig. 5 yields a mean value of $0.412 \times 10^{-3} \mathrm{rad} / \mathrm{m}$, which is only $1.2 \%$ higher than the analytical results.

Examination of Fig. 5 also reveals that the ductility demand of rocking pier is always less than $1.0\left(\ln \left(\mu_{\phi}\right)<0\right)$, indicating that the pier column remains elastic and undamaged for all earthquake excitations considered. Furthermore, when uplifting initiates (shown in red circle), the rocking pier yields similar responses under different input motions. Similar tendency could be observed in Table 4, in which the $\beta_{\mathrm{D} \mid \mathrm{IM}}(0.07)$ of strong excitations (PGV $>90 \mathrm{~cm} / \mathrm{s}$ ) only accounts for $22.5 \%$ and $10.9 \%$ that of moderate excitation $\left(\mathrm{PGV}<90 \quad \mathrm{~cm} / \mathrm{s}, \quad \beta_{\mathrm{D} \mid \mathrm{IM}}=0.310\right)$ and prototype $\left(\beta_{\mathrm{D} \mid \mathrm{IM}}=0.638\right)$. This phenomenon indicates that the seismic demands of rocking pier under strong earthquakes are mainly independent of ground motion characters, which significantly benefits the prediction of post-earthquake states of these structures.

\subsection{Fragility curves}

Figure 6 presents the fragility curves for both prototype and rocking piers, in which the PGV (i.e., $I M$ ) value plotted in lateral axis is up to $350 \mathrm{~cm} / \mathrm{s}$, corresponding to the maximum value of selected motions (Table 1). Note that when rocking foundation is employed, the probability of exceeding moderate damage is only $0.54 \%$ with PGA $=$ $350 \mathrm{~cm} / \mathrm{s}$, which is negligible in engineering practice. Therefore, the fragility curves of more severe damage states (extensive and complete) are not presented for discussion. Since bi-linear regression is used to construct the PSDM of rocking pier, the fragility curves are composed of two parts as well, with the critical PGV around $90 \mathrm{~cm} / \mathrm{s}$ (denoted as initiation of rocking).
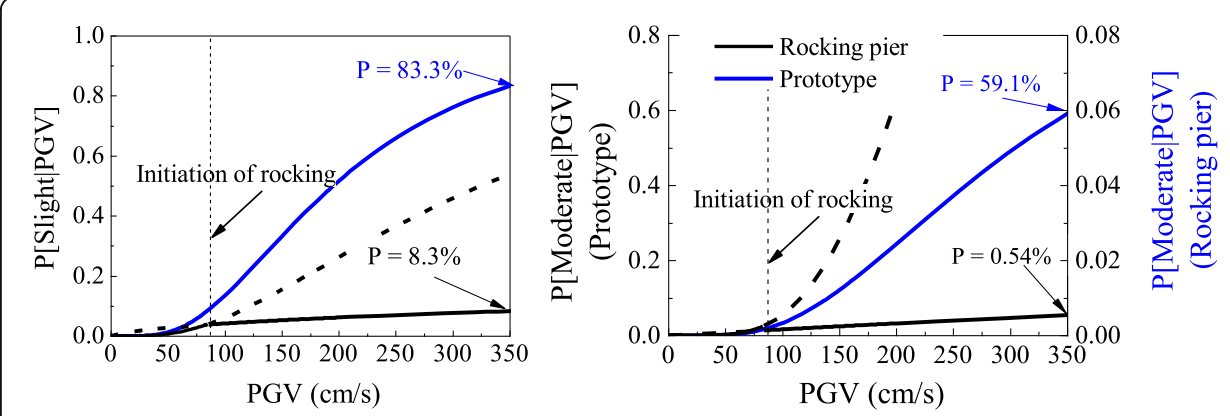

Fig. 6 Comparisons of fragility curves 
From the results shown in Fig. 6, the rocking foundation is observed able to effectively reduce the seismic vulnerability of tall piers for both damage limit states; while the conclusion for extensive and complete damage states is similar. With the employment of rocking foundation, the probability of being damaged of the prototype tall pier reduces from $83.3 \%$ and $59.1-8.3 \%$ and $0.54 \%$, respectively, for slight and moderate damage.

\section{Conclusions}

This paper investigates the efficiency of improving seismic performance of tall pier bridges using rocking foundation, with the results presented in the format of fragility curves. Based on the analysis, the main conclusion are as follows:

(1) Employment of rocking foundation at pier base could significantly reduce the seismic vulnerability of tall piers. Since rocking piers generally remain elastic after earthquake events, these bridges could function as lifelines during post-earthquake rescue operations.

(2) When subjected to moderate excitations (PGV $<90 \mathrm{~cm} / \mathrm{s}$ in current study), seismic behavior of rocking piers resembles that of integrated ones, since rocking interface remains contact. While rocking initiates during strong excitations, the seismic performance of tall piers is drastically improved by rocking foundations.

(3) Once the seismic behavior is dominated by the rocking vibration mode, the section curvature ductility demands of piers tend to be independent of characteristics of input motions. Thus, the designers could provide reliable prediction for postearthquake states of rocking piers, which benefits developing rescue plans in advance.

Note that current investigation mainly focuses on the seismic performance of tall pier columns, while the potential influence of water and soil layers is not incorporated. These issues will be considered in future works to provide more comprehensive insights.

Acknowledgements

Not applicable.

Authors' contributions

Xu Chen: Conceptualization, Data curation, Formal analysis, Funding acquisition, Investigation, Methodology, Writing original draft. Jianzhong Li: Methodology, Project administration, Resources, Writing - review \& editing. All authors read and approved the final manuscript.

Funding

This study is supported by the National Natural Science Foundation (No. 51908348).

Availability of data and materials

The data and materials in current study are available from the corresponding author on reasonable request.

Competing interests

The authors declare that they have no competing interests. 
Received: 3 December 2020 Accepted: 10 December 2020

Published online: 19 February 2021

\section{References}

Alam M, Bhuiyan M, Billah A (2012) Seismic fragility assessment of SMA-bar restrained multi-span continuous highway bridge isolated by different laminated rubber bearings in medium to strong seismic risk zones. Bull Earthq Eng 10(6):1885-1909

Chen X (2020) System Fragility Assessment of Tall-Pier Bridges Subjected to Near-Fault Ground Motions. J Bridge Engineering 25(3):14

Chen X, Guan Z (2020) Extension of a simplified procedure for estimating nonlinear seismic responses of tall pier bridge systems. European Journal of Environmental and Civil Engineering: 1-20

Chen X, Li C (2020a) Seismic assessment of earthquake-resilient tall pier bridges using rocking foundation retrofitted with various energy dissipation devices. Structural Control \& Health Monitoring

Chen X, Li C (2020b) Seismic performance of tall pier bridges retrofitted with lead rubber bearings and rocking foundation. Eng Struct 212:1-15

Chen C, Yeh K, Liu K (2009) Adaptive fuzzy sliding mode control for seismically excited bridges with lead rubber bearing isolation. International Journal of Uncertainty Fuzziness Knowledge-Based Systems 17(05):705-727

Chen X, Li J, Guan Z (2016) Effects of higher modes on tall piers. IABSE Symposium Report, International Association for Bridge and Structural Engineering

Chen X, Guan Z, Li J, Spencer B Jr (2018a) Shake Table Tests of Tall-Pier Bridges to Evaluate Seismic Performance. J Bridge Engineering 23(9):04018058

Chen X, Guan Z, Spencer B Jr, Li J (2018b) A simplified procedure for estimating nonlinear seismic demand of tall piers. Eng Struct 174:778-791

Chen X, Guan Z, Li J (2019) Fragility Analysis of Tall Pier Bridges Subjected to Near-fault Pulse-like Ground Motions. Structure and Infrastructure Engineering

Cornell C, Jalayer F, Hamburger R, Foutch D (2002) Probabilistic basis for 2000 SAC federal emergency management agency steel moment frame guidelines. Journal of structural engineering 128(4):526-533

Deng Y, Guo Q, Xu L (2017) Experimental and Numerical Study on Modal Dynamic Response of Water-Surrounded Slender Bridge Pier with Pile Foundation. Shock Vibration 2017:4769637

Dowdell D, Hamersley B (2000) Lions' Gate Bridge North Approach: Seismic retrofit. Behaviour of Steel Structures in Seismic Areas: Proc., 3rd Int. Conf.: STESSA 2000, Balkema

Gardoni P, Mosalam K, Kiureghian A (2003) Probabilistic seismic demand models and fragility estimates for RC bridges. Journal of earthquake engineering 7(spec01):79-106

Guirguis J, Mehanny S (2012) Evaluating code criteria for regular seismic behavior of continuous concrete box girder bridges with unequal height piers. J Bridge Engineering 18(6):486-498

Jangid R (2007) Optimum lead-rubber isolation bearings for near-fault motions. Journal of Engineering Structures 29(10): 2503-2513

Kelly J, Konstantinidis D (2011) Mechanics of rubber bearings for seismic and vibration isolation, John Wiley \& Sons

LiU S, Li Y, Li G (2007) WAVE CURRENT FORCES ON THE PILE GROUP OF BASE FOUNDATION FOR THE EAST SEA BRIDGE, CHIN A. Journal of Hydrodynamics 19(6): 661-670

Luco N, Cornell C (2007) Structure-specific scalar intensity measures for near-source and ordinary earthquake ground motions. Earthquake Spectra 23(2):357-392

Nielson B, DesRoches R (2007) Seismic fragility methodology for highway bridges using a component level approach Earthquake Eng Struct Dynam 36(6):823-839

Padgett J, DesRoches R (2008) Methodology for the development of analytical fragility curves for retrofitted bridges. Earthquake Engineering Structural Dynamics 37(8):1157-1174

Padgett J, Nielson B, DesRoches R (2008) Selection of optimal intensity measures in probabilistic seismic demand models of highway bridge portfolios. Earthquake Engineering Structural Dynamics 37(5):711-725

Phan V, Saiidi M, Anderson J, Ghasemi H (2007) Near-fault ground motion effects on reinforced concrete bridge columns. Journal of structural engineering 133(7):982-989

Scott B, Park R, Priestley M (1982) Stress-strain behavior of concrete confined by overlapping hoops at low and high strain rates. Journal Proceedings

Sica S, Mylonakis G, Simonelli A (2013) Strain effects on kinematic pile bending in layered soil. Soil Dyn Earthq Eng 49:231242

Solberg K, Mashiko N, Mander J, Dhakal R (2009) Performance of a damage-protected highway bridge pier subjected to bidirectional earthquake attack. Journal of structural engineering 135(5):469-478

Tekie P, Ellingwood B (2003) Seismic fragility assessment of concrete gravity dams. Earthquake engineering structural dynamics 32(14):2221-2240

Wang X, Ye A. and Ji B (2019) Fragility-based sensitivity analysis on the seismic performance of pile-group-supported bridges in liquefiable ground undergoing scour potentials. Eng Struct 198:109427

Xie Y, Zhang J, DesRoches R, Padgett J (2019) Seismic fragilities of single-column highway bridges with rocking columnfooting. Earthquake engineering structural dynamics 48(7):843-864

Yamamoto M, Minewaki S, Yoneda H, Higashino M (2012) Nonlinear behavior of high-damping rubber bearings under horizontal bidirectional loading: full-scale tests and analytical modeling. Earthquake Eng Struct Dynam 41(13):1845-1860

Yashinsky M, Karshenas M (2003) Fundamentals of seismic protection for bridges, National Information Centre of Earthquake Engineering

Zhao G, Xu L, Xie L (2016) A simple and quantitative algorithm for identifying pulse-like ground motions based on zero velocity point method. Bull Seismol Soc Am 106(3):1011-1023

\section{Publisher's Note}

Springer Nature remains neutral with regard to jurisdictional claims in published maps and institutional affiliations. 